\title{
The neural cell adhesion molecule-derived peptide FGL facilitates long-term plasticity in the dentate gyrus in vivo
}

\author{
Glenn Dallérac, ${ }^{1,5}$ Meike Zerwas, ${ }^{2}$ Tatiana Novikova, ${ }^{3}$ Delphine Callu, ${ }^{1}$ Pascale Leblanc- \\ Veyrac, ${ }^{1}$ Elisabeth Bock, ${ }^{4}$ Vladimir Berezin, ${ }^{4}$ Claire Rampon, ${ }^{2}$ and Valérie Doyère ${ }^{1,6}$ \\ ${ }^{1}$ Centre de Neurosciences Paris-Sud, Université Paris-Sud XI, CNRS-UMR8195, 91405, Orsay, France; ${ }^{2}$ Centre de Recherches sur \\ la Cognition Animale, CNRS UMR5169, Université Paul Sabatier, Toulouse, France; ${ }^{3}$ ENKAM Pharmaceuticals A/S, Fruebjergvej 3, \\ DK-2100, Copenhagen, Denmark; ${ }^{4}$ Protein Laboratory, Copenhagen University, Blegdamsvej 3, DK-2200, Copenhagen, Denmark
}

\begin{abstract}
The neural cell adhesion molecule (NCAM) is known to play a role in developmental and structural processes but also in synaptic plasticity and memory of the adult animal. Recently, FGL, a NCAM mimetic peptide that binds to the Fibroblast Growth Factor Receptor 1 (FGFR-1), has been shown to have a beneficial impact on normal memory functioning, as well as to rescue some pathological cognitive impairments. Whether its facilitating impact may be mediated through promoting neuronal plasticity is not known. The present study was therefore designed to test whether FGL modulates the induction and maintenance of synaptic plasticity in the dentate gyrus (DG) in vivo. For this, we first assessed the effect of the FGL peptide on synaptic functions at perforant path-dentate gyrus synapses in the anesthetized rat. FGL, or its control inactive peptide, was injected locally 60 min before applying high-frequency stimulation (HFS) to the medial perforant path. The results suggest that although FGL did not alter basal synaptic transmission, it facilitated both the induction and maintenance of LTP. Interestingly, FGL also modified the heterosynaptic plasticity observed at the neighboring lateral perforant path synapses. The second series of experiments, using FGL intracerebroventricular infusion in the awake animal, confirmed its facilitating effect on LTP for up to $24 \mathrm{~h}$. Our data also suggest that FGL could alter neurogenesis associated with LTP. In sum, these results show for the first time that enhancing NCAM functions by mimicking its heterophilic interaction with FGFR facilitates hippocampal synaptic plasticity in the awake, freely moving animal.
\end{abstract}

[Supplemental material is available for this article.]

Neural cell adhesion molecules (NCAMs) are complexes of transmembranal proteins critical for cell-cell interactions. They are recognition molecules of the immunoglobulin (Ig) superfamily, and are widely believed to play a critical role in developmental processes such as cell migration, cell survival, axon guidance, and synaptic targeting (for review, see Maness and Schachner 2007). Recent developments demonstrate that NCAMs are also important in the mature adult brain, where acute disruption of NCAM function with antibodies in vitro or chronic alteration of NCAM function in knock-out mice impairs synaptic plasticity and memory formation (Ronn et al. 1995; Luthi et al. 1996; Stoenica et al. 2006). To date, three isoforms of the NCAM molecule have been described, namely NCAM120, NCAM140, and NCAM180. Their extracellular domains all contain five Ig and two fibronectin type III (FnIII) domains. Although Ig motifs engage in homophilic interactions, the FnIII domains have been found to contain heterophilic binding sites (Hinsby et al. 2004a,b; Walmod et al. 2004; Ditlevsen et al. 2008). Although the specific function of each binding site remains unidentified,

\footnotetext{
${ }^{5}$ Present address: Institut François Magendie, Centre de Recherche INSERM, U862, Equipe "Physiologie intégrée des systèmes neuroendocrines," 146 rue Léo Saignat, 33077 Bordeaux, France.

${ }^{6}$ Corresponding author.

E-mail valerie.doyere@u-psud.fr; fax (33) 169157726.

Article is online at http://www.learnmem.org/cgi/doi/10.1101//m.2154311.
}

it is of interest to note that one of them binds to the Fibroblast Growth Factor Receptor 1 (FGFR-1), a receptor required for synaptic plasticity and the generation of new neurons in the adult brain (Zhao et al. 2007).

Recently, mimetic peptides of specific cell adhesion molecules' binding motifs have been developed. In particular, the peptide FGL was generated in order to mimic the NCAM FGFR-1 binding site (Kiselyov et al. 2003). In vitro, FGL induces phosphorylation that activates the FGFR-1 (Kiselyov et al. 2003) and exhibits similar neuritogenic and survival effects as NCAM, an effect abrogated by inhibition of FGFR activation (Neiiendam et al. 2004). FGL also enhances presynaptic release in hippocampal cell culture (Cambon et al. 2004). In vivo, chronic administration of the peptide improves associative, spatial as well as social memory, and reduces phencyclidine-induced impairment in spatial learning (Cambon et al. 2004; Secher et al. 2006, 2009). Remarkably, a single acute administration of FGL appears sufficient to alleviate $A \beta$, or ischemia-induced neuropathology and cognitive impairment (Skibo et al. 2005; Klementiev et al. 2007; Secher et al. 2009). Further, a recent study by Stewart and colleagues demonstrated that FGL treatment alters spine morphology and synapse distribution (Stewart et al. 2010). Together these reports suggest that NCAM stimulation of FGFRs regulates neural connectivity. Whether the expression of these alterations relies on changes in synaptic transmission and plasticity remains unknown. 
In the present study, we thus sought to determine whether acute stimulation of the FGFR-1 by the FGL peptide affects basal synaptic properties and plasticity in the dentate gyrus (DG) in vivo. FGL has indeed been shown to influence connectivity in the DG (Popov et al. 2008; Stewart et al. 2010), as well as in hippocampal-dependent memories (Cambon et al. 2004; Secher et al. 2009); further, FGFR1 have been shown to influence plasticity in the DG (Zhao et al. 2007). The cellular mechanisms associated with long-term potentiation (LTP) in the first hours following its induction are thought to primarily involve posttranslational modifications (Bliss and Collingridge 1993). In contrast, late-phase LTP is dependent upon gene expression and is correlated with eventual morphological modification (Yuste and Bonhoeffer 2001; Bozon et al. 2003). We first analyzed the effect of FGL on basal synaptic function, local circuit regulation, as well as short-term and early phase of long-term plasticity (up to $3 \mathrm{~h}$ ) in the anesthetized rat. In a second set of experiments, we focused on the long-term phase of LTP $(24 \mathrm{~h})$ in the awake rat. In addition, insofar as the FGL peptide stimulates a growth factor receptor and that LTP has been shown to increase adult neurogenesis, another form of plasticity in the DG (Bruel-Jungerman et al. 2006), we also assessed in these chronically recorded rats whether FGL, alone or in interaction with LTP, alters new cell proliferation in the hippocampus.

\section{Results}

\section{FGL alters early phases of synaptic plasticity in the dentate gyrus}

\section{FGL does not alter basal synaptic transmission}

To ascertain whether the activation of FGFR with FGL influences basal synaptic efficacy, baseline recordings were collected $30 \mathrm{~min}$ (FGL $n=15$, FGLdiala $n=13$ ) before and $270 \mathrm{~min}$ (FGL $n=4$, FGLdiala $n=5$ ) after local infusion of FGL or control FGLdiala in the anesthetized animal. We verified that I/O plots performed prior to baseline recordings and peptides administration were similar in the FGL and FGLdiala groups $\left(F_{\mathrm{s}}<1\right.$, for both MPP and LPP). Although local delivery of the peptide induced a reduction in the field EPSP slope (Fig. 1A), there was no significant difference between groups (30 min, MPP $F<1$, LPP $F<1 ; 270 \mathrm{~min}$, MPP $F<1$, LPP $F<1$ ), indicating that FGL had no significant effect on basal synaptic transmission, and that the decrease on the EPSP slope was most probably attributable to mechanical pressure due to the local infusion delivery method as infusion of a saline solution $(0.9 \% \mathrm{NaCl})$ induced the same depression (30 min, $n=6, F<1 ; 270 \mathrm{~min}, n=3, F<1$; data not shown). Following peptide delivery, the stability of the preparation was recovered after $60 \mathrm{~min}$ on average. No effect was observed on the population spike amplitude (data not shown).

\section{FGL does not alter paired-pulse function}

Paired-pulse tests collected before and for $270 \mathrm{~min}$ after FGL or FGLdiala infusions were compared in order to assess the effect of FGL on local network regulation. In agreement with previous investigations (McNaughton 1980; Bordi et al. 1997; Wang et al. 2001; Fueta et al. 2002), paired pulses administered in the control FGLdiala group to the MPP resulted in a slight inhibition of the population spike (PS) at $20 \mathrm{msec}$ ISI, which is thought to be mainly attributable to recurrent inhibition via granule cell firing (Andersen et al. 1964; Alger and Nicoll 1980; Fricke and Prince 1984). This early suppression was followed by facilitation at $70 \mathrm{msec}$ ISI, which returned to baseline at $500 \mathrm{msec}$ ISI (Fig. 1B). Such facilitation also corroborates previous findings
(McNaughton 1980; Racine and Milgram 1983; Steffensen and Henriksen 1991). Paired-pulse stimulation of the LPP showed no change at $20 \mathrm{msec}$ ISI and facilitation up to $500 \mathrm{msec}$ ISI, which also confirms previous reports (McNaughton 1980; Ruan et al. 1998). FGL did not have any significant effect on these pairedpulse functions for either pathway (LPP-LPP, treatment: $F<1$, treatment $\times$ ISI interaction: $F<1$; MPP-MPP, treatment: $F<1$, treatment $\times$ ISI interaction: $\left.F_{(2,42)}=2.03, P=0.14\right)$. Also, no effect of FGL was found on the paired-pulse curve for EPSP slope (data not shown). Thus, activation of the FGFR with FGL seems to have no effect on either short-term plasticity or on local inhibitory regulation in the dentate gyrus in vivo.

\section{FGL facilitates early LTP}

As NCAM functions have been reported to be necessary for the induction of LTP (Ronn et al. 1995; Luthi et al. 1996; Stoenica et al. 2006), we sought to determine whether the FGL peptide could facilitate LTP induced with a weak HFS protocol (10 series, $1 \mathrm{~min}$ apart, of three trains of pulses- $400 \mathrm{~Hz}, 20 \mathrm{msec}$ - at 1-sec interval at test intensity). Focusing on the LTP induction phase, we found that post-tetanic potentiation (PTP) measured during the first 2 min after HFS was significantly increased under FGL treatment (FGL: $134.79 \pm 3.64 \%$ of baseline, $n=7$; FGLdiala: $124.06 \pm 4.72 \%$ of baseline, $\left.n=8 ; F_{(1,13)}=4.96, P=0.04\right)$, suggesting that FGL may have an effect on presynaptic events occurring during and immediately after sustained repetitive stimulation.

With respect to the maintenance phase, as expected the weak HFS protocol to give rise to a decaying LTP reaching $113.14 \pm$ $4.79 \%$ of baseline EPSP slope $3 \mathrm{~h}$ after induction in the FGLdiala control group (Fig. 1C). In contrast, LTP was found to be significantly enhanced and more maintained in the presence of FGL, persisting at $127.48 \pm 5.43 \%$ of baseline $3 \mathrm{~h}$ post-HFS (Fig. 1C) (FGLdiala $n=8$; FGL: $n=7 ; F_{(1,13)}=5.16, P=0.04$, time $\times$ treatment interaction upon $\left.3 \mathrm{~h}: F_{(116,1508)}=1.77, P<0.001\right)$. In addition, the slope of the linear regression line obtained in the FGL group $\left(0.15<R^{2}<0.57\right)$ did not significantly deviate from zero (FGL slope $=-0.00013 \pm 0.0072 \%$ change $/ \mathrm{min}, P=0.99$, $F_{(1,824)}<1 ; F$-test, GraphPad Prism software version 4.0), whereas this deviation was clearly significant in the FGLdiala control group $\left(0.14<R^{2}<0.53\right.$; FGLdiala slope $=-0.045 \pm 0.0077 \%$ change $\left./ \mathrm{min}, P<0.001, F_{(1,942)}=34.21\right)$. The same trend was observed for the population spike, but remained under significance, possibly due to the large variability of the spike amplitude. The difference in decay function for the EPSP slope suggests that FGL may facilitate the maintenance phase of LTP, in addition to its facilitative effect on the LTP induction.

\section{FGL modifies heterosynaptic plasticity}

Heterosynaptic plasticity was analyzed through the recordings of the EPSP elicited by stimulation of the LPP. Unexpectedly, the local activation of the FGFR during MPP-LTP induction resulted in a heterosynaptic potentiation of the EPSP slope for the nonstimulated LPP (Fig. 1D). Although FGLdiala animals showed no heterosynaptic potentiation of LPP EPSP slope after MPP-LTP, as previously reported (Doyère et al. 1997), FGL animals showed an immediate and lasting increase in LPP EPSP slope. Between groups differences were significant up to $90 \mathrm{~min}$ post-HFS (FGLdiala: $102.88 \pm 3.06 \%$ of baseline, $n=8$; FGL: $114.94 \pm 4.69 \%$ of baseline, $\left.n=7 ; F_{(1,13)}=4.87, P=0.04\right)$ and remained marginally significant at $3 \mathrm{~h}$ post-HFS (Fig. 1D) (FGLdiala: $104.37 \pm 4.61 \%$ of baseline, FGL: $121.14 \pm 8.38 \%$ of baseline, $\left.F_{(1,13)}=3.83, P=0.07\right)$.

Despite the fact that the summation tests carried out before the experiment indicated good selectivity and that the 
A

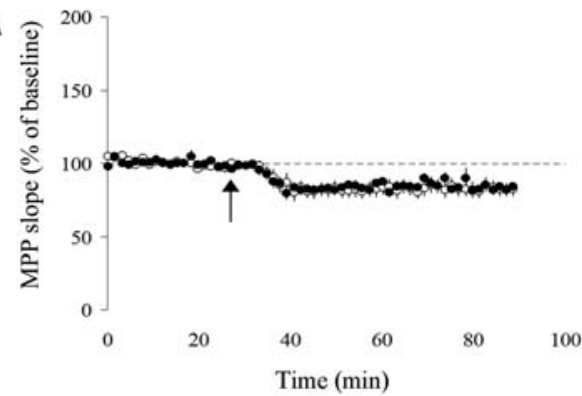

B

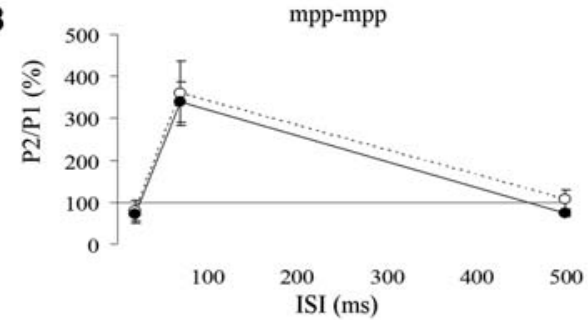

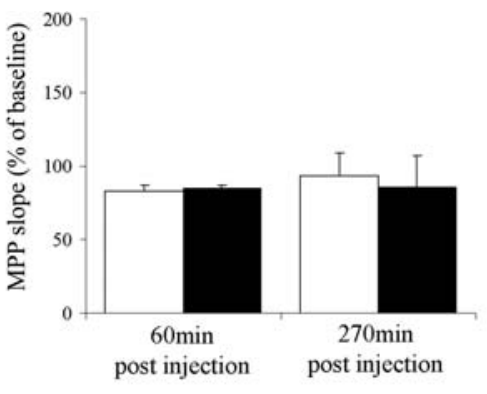

lpp-Ipp

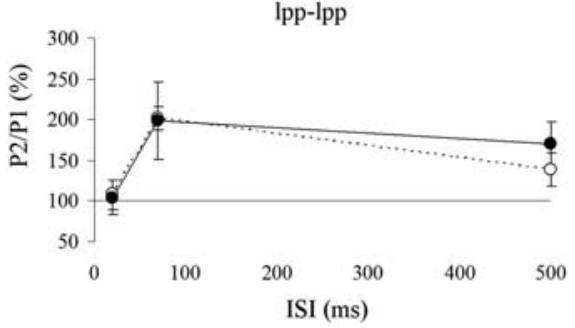

C

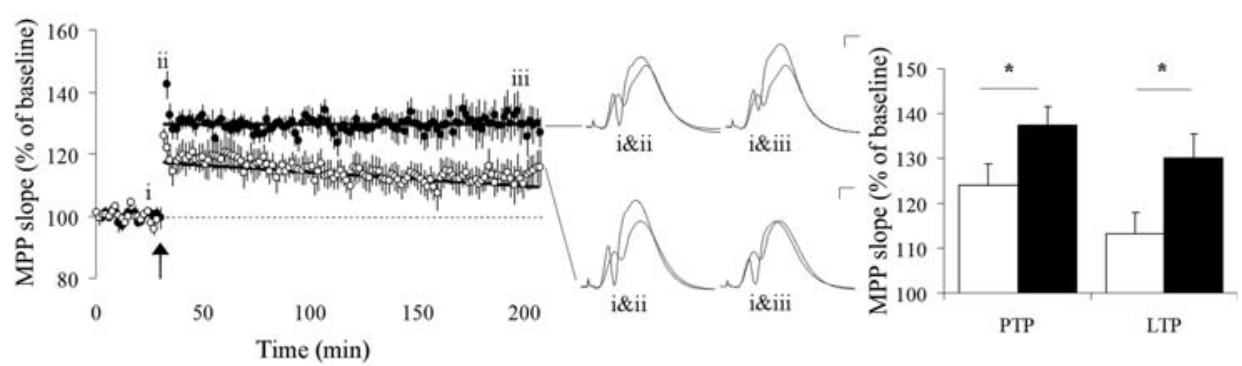

D

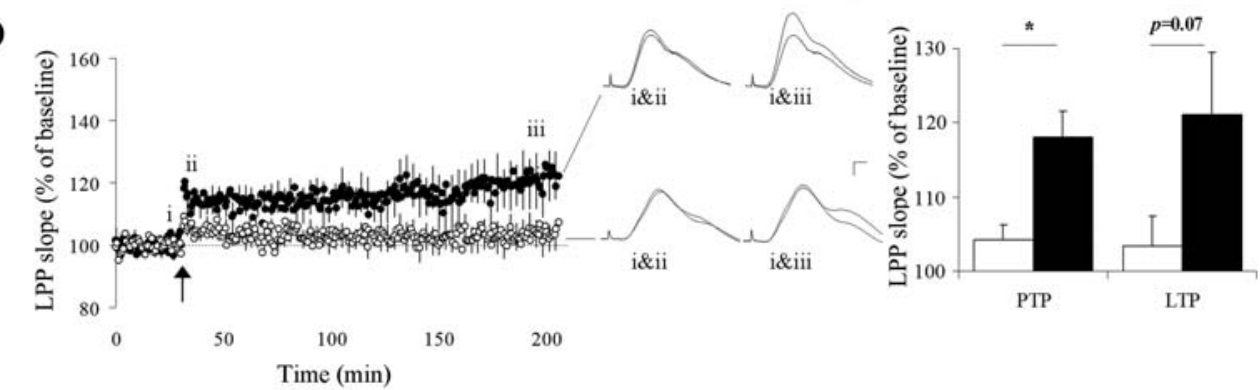

Figure 1. Effect of FGL $(\bullet)$ compared to control inactive peptide FGLdiala ( $)$ on synaptic transmission and plasticity in the DG in vivo. $(A)$ The pressure engendered by infusion of the peptide $(\uparrow)$ decreased EPSP slope in the same manner for the FGL $(\bullet)$ and control (O) groups. Thus, FGL did not alter basal synaptic transmission. (B) Paired-pulse profiles for 20-, 70-, and 500-msec interstimulus intervals (ISI) were found to be similar between groups suggesting that FGL did not influence local circuit regulation. PS1: population spike 1, PS2: population spike 2. (C) EPSP slope measurements of MPP field potentials (insets) over time showed that PTP measured during the first 2 min after HFS $(\uparrow)$ was significantly increased $(P=0.04)$ and LTP was more sustained $3 \mathrm{~h}$ post-induction in the FGL group $(P=0.04)$. $(D)$ FGL enabled the heterosynaptic potentiation of EPSP slope of LPP field potentials (insets) after HFS on MPP. This potentiation remained significant up to 90 min post-HFS $(P=0.04)$. LPP: lateral perforant path, MPP: medial perforant path. Calibration bars: $2 \mathrm{msec}, 1 \mathrm{mV}$. Data are expressed as \pm SEM.

characteristic shape of the LPP field potentials did not change after HFS, the slight facilitation observed in the control group shortly after HFS of the MPP may suggest a reduced selectivity over time. To verify that the selectivity remained intact, we took advantage of the characteristic latencies of the LPP and MPP field potentials, known to differ at the onset (McNaughton and Barnes 1977; Abraham and McNaughton 1984; Doyère et al. 1997). We therefore analyzed the onset latency of both signals over the entire experiment for every animal of FGL and FGLdiala groups. As expected in the case of good separation, the onset latency of
MPP EPSPs was significantly shorter than for LPP EPSPs in both groups, during baseline (FGL $P<0.001$, FGLdiala $P=$ 0.008 , paired bilateral $t$-test), PTP (FGL $P<0.001$, FGLdiala $P=$ 0.001 ), and upon the whole time course of LTP (FGL $P<0.001$, FGLdiala $P=0.04)$. Besides, the onset of LPP potentials was not reduced after HFS, neither during PTP (FGL: baseline vs. PTP $P=$ 0.3, FGLdiala: baseline BL vs. PTP $P=0.9$ ), nor during LTP (FGL: baseline vs. LTP $P=0.4$, FGLdiala: baseline vs. LTP $P=0.9$ ), confirming that the stimulation of the LPP did not recruit MPP fibers. Therefore, both the summation test and analysis of the EPSPs 
onset indicate that the potentials recorded were selective for each pathway, implying that the potentiation of the LPP EPSP observed in the FGL group does reflect heterosynaptic processes. This heterosynaptic potentiation might thus suggest that FGL may act also post-synaptically.

\section{FGL enhances late LTP in the awake rat}

\section{Immunohistochemical detection of the FGL peptide}

The presence of FGL in the DG was assessed using immunohistochemistry directed against FGL peptide 10, 30, 60, or $120 \mathrm{~min}$ after a single icv administration of FGL in the right lateral ventricle ( $n=4$ in each group). Our data showed that FGL diffused from the lateral ventricle to the septum, cortex, and striatum (Fig. 2A) in addition to the hippocampus where it was detected in the DG as early as 10 and 30 min post-injection. The FGL peptide was found at the ependymal surface of the right ventricle and adjacent brain parenchyma, including the septum nuclei, DG, CA1, and CA3 areas of the hippocampus and the cortical area surrounding the cannula track (Fig. 2A). Double immunostaining for FGL and NeuN showed FGL localization in cortical, septal, and hippocampal neurons (Fig. 2B-L). DAB peroxidase immunocytochemistry images (Fig. 2B,C) clearly show FGL to be present within the cell as well as on the cell membrane. This is most probably attributable to endocytosis of receptor-ligand (FGFR-1-FGL) complexes.

The diffusion of FGL into the DG remained stable over the next hours as indicated by FGL immunoreactivity found on brain sections of animals perfused 1 or $2 \mathrm{~h}$ after FGL administration (Fig. 2D-F). Similar observations were made concerning the distribution of FGL into the hippocampal CA1 and CA3 subregions $2 \mathrm{~h}$ after the icv infusion (Fig. 2G-L).

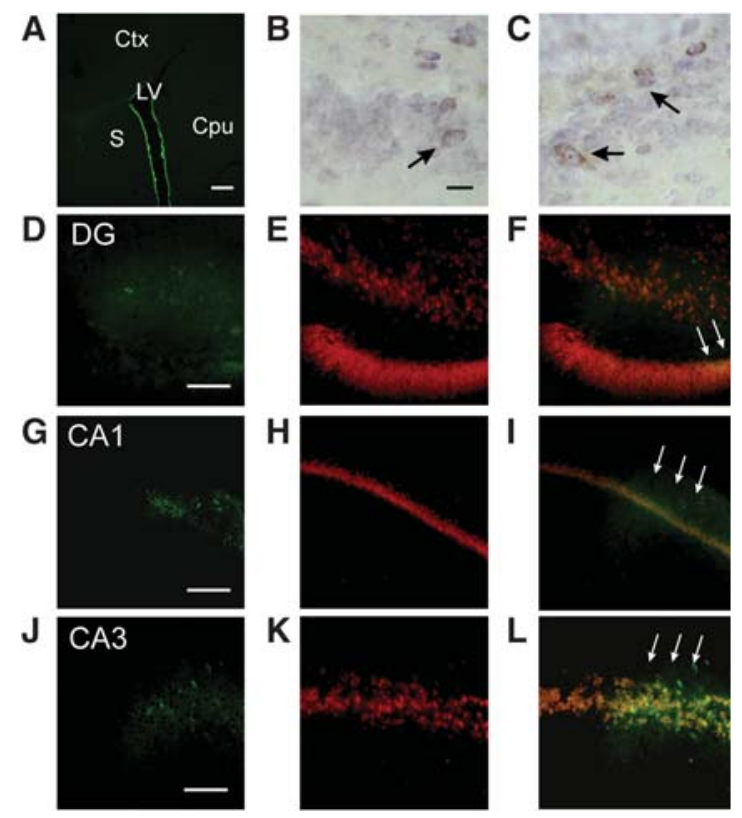

Figure 2. Diffusion of FGL following icv injection. (A) FGL (green) peptide was present on the area surrounding the cannula track and in the adjacent brain parenchyma. $(B, C)$ : FGL (brown) was detected in the DG by DAB peroxidase immunocytochemistery $10 \mathrm{~min}(B)$ and $30 \mathrm{~min}$ (C) after icv injection. ( $D-L)$ The FGL antibodies fluorescent signal was still present in the DG $(D-F), C A 1(G-I)$, and CA3 $(J-L) 120$ min postinjection. CPu: Caudate Putamen, Ctx: cortex, LV: lateral ventricule, S: septum. Arrows indicate FGL-immunopositive cells. Scale bars: $200 \mu \mathrm{m}$ $(A), 20 \mu \mathrm{m}(B, C), 80 \mu \mathrm{m}(D-L)$.

\section{FGL enhances LTP up to $24 \mathrm{~h}$}

The I/O relationships were similar between groups. Baseline recordings confirmed that the FGL peptide did not alter basal synaptic transmission (Fig. 3), 20 min (all animals: FGLdiala: $94.62 \pm$ $2.70 \%$ of baseline, $n=12$; FGL: $103.39 \pm 1.38 \%$ of baseline, $n=$ $14 ; F<1$ ) or $24 \mathrm{~h}$ (animals from pseudo-tetanus groups, [Fig. 3, bottom panel] FGLdiala: $87.31 \pm 13.70 \%$ of baseline, $n=5$; FGL: $113.76 \pm 3.86 \%$ of baseline, $n=6 ; F<1$ ) after icv infusion.

Crucially, LTP tested $24 \mathrm{~h}$ after its induction was still significantly higher in the FGL group (Fig. 3, upper panel) (FGLdiala: $116.96 \pm 7.60 \%$ of baseline, $n=7$; FGL: $140.26 \pm 8.77 \%$ of baseline, $\left.n=8 ; F_{(1,13)}=4.58, P=0.05\right)$, showing that FGL facilitation of potentiation is maintained in the late phases of LTP in vivo. Such a finding is essential for the interpretation of this effect in terms of learning and memory.

\section{Effect of FGL and LTP on cell proliferation}

To evaluate whether the application of FGL together with LTP induction has an effect on neural progenitor cell proliferation in the DG, we counted the number of cells expressing the proliferation marker Ki67. Ki67 is an endogenous marker of cell proliferation, which is only expressed during the active period of the cell cycle and is absent when the cell is quiescent (Kee et al. 2002). Ki67-immunoreactive $\left(\mathrm{Ki} 67^{+}\right)$cells were primarily observed in the subgranular zone of the DG, where the hippocampal progenitor cells are located (Fig. 4A). As strikingly evident in Figure 4, FGL had a strong impact on the variance ( $F$-test for equality of variances between FGL and FGLdiala, $\left.F_{(9,9)}=3.33, P=0.04\right)$. Therefore, for each given comparison, we first tested for the equality of variance ( $F$-test), and then applied the corresponding unpaired $t$-test. We observed that LTP enhanced cell proliferation both in the FGLdiala group (unpaired $t$-test for equal variances: $t_{(8)}=$ $2.75, P<0.03$ ) and in the FGL group (unpaired $t$-test for unequal variances: $\left.t_{(5)}=2.56, P=0.05\right)$ in agreement with our previous report (Bruel-Jungerman et al. 2006). Although FGL did not seem to modify the cell proliferation on average, neither in Pseudo nor HFS conditions, it may possibly act in interaction with HFS as among the pairs of comparisons, the inequality of variances was the most pronounced between FGL-HFS and FGL-pseudo groups $\left(F_{(5,3)}=86.19, P=0.002\right)$. Thus, these data suggest that activation of the FGFR by the peptide might disturb the proliferation associated with LTP. Besides, we found that the coefficient of determination of the regression between the level of LTP and the number of $\mathrm{Ki} 67^{+}$cells in the FGL-HFS group only reached $R^{2}=0.48$. Further, the $Z$-test for correlation indicates that these data are not significantly correlated $(P=0.22)$. Therefore, the significant increase in variability in cell proliferation associated with LTP cannot be solely attributed to different magnitudes of potentiation in the FGL-LTP group.

\section{Discussion}

It is now widely believed that neural cell adhesion molecules underlie substantial function in synaptic plasticity. Evidence for such a role comes from studies producing a loss or reduction of NCAM function using pharmacological compounds or genetically modified animals (Luthi et al. 1994; Ronn et al. 1995; Becker et al. 1996; Eckhardt et al. 2000; Stoenica et al. 2006). However, no investigation has yet tested whether enhancing NCAM function could impact synaptic plasticity. We provide here the first study showing that enhancing NCAM function by mimicking its heterophilic interaction with FGFR facilitates synaptic plasticity. This finding is essential for our understanding of how cell adhesion molecules regulate plasticity. 


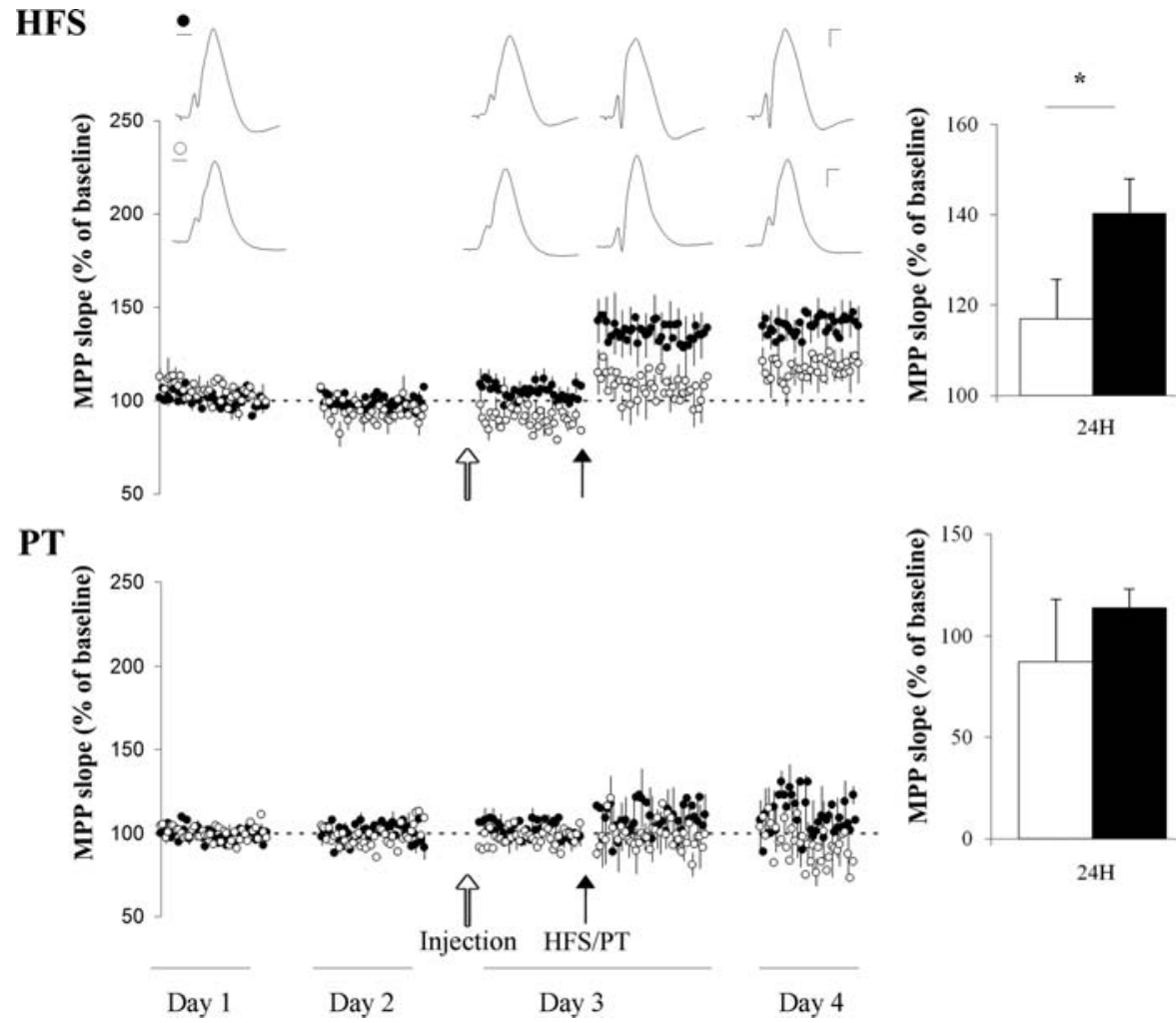

Figure 3. FGL enhances late LTP in the awake animal. LTP was found to be significantly enhanced in awake rats injected with FGL $(\bullet) 24 \mathrm{~h}(P=0.05)$ post-HFS. Synaptic transmission was unaltered in animals that were administered pseudo-tetanus (PT) and injected with either peptide. Calibration bars: $2 \mathrm{msec}, 1 \mathrm{mV}$. Data are expressed as \pm SEM.

FGL did not affect basal synaptic transmission or pairedpulse plasticity for short and long ISI, suggesting that local inhibitory mechanisms are not altered by the presence of the peptide. However, after administration of HFS, FGL was found to facilitate both PTP and LTP up to $3 \mathrm{~h}$ post-HFS in the anesthetized rat and up to $24 \mathrm{~h}$ post-HFS in the awake rat. Although FGL is likely to stimulate the FGFR differently than the FGFs molecules (Hinsby et al. 2004a,b; Kiselyov et al. 2005) and may act also on other receptors, this result corroborates the investigation of Zhao and colleagues reporting a severe impairment of in vitro MPP-LTP in the Fgfr1 conditional knock-out mouse (Zhao et al. 2007) and an earlier study showing that icv injection of human acidic FGF facilitates the generation of LTP by a weak tetanus in the awake rat (Hisajima et al. 1992). Interestingly however, a recent study reports that FGL alleviated the deficiency in LTP displayed by aged rats, but had no effect on LTP $1 \mathrm{~h}$ post-induction in young Wistar rats in vivo (Downer et al. 2010). This apparent discrepancy is most probably attributable to the fact that in these experiments, FGL was administered subcutaneously, a procedure that in our hands did not reveal any difference in LTP either (Supplemental Fig. 1) (FGL: $109.32 \pm 3.39 \%$ of baseline, $n=4$; control: $113.99 \pm 8.64 \%$ of baseline, $n=4 ; F<1$, ns). All together, these results suggest that the peptide can facilitate LTP in normal conditions, as well as in impaired conditions such as during aging, provided that a higher dose reaches the hippocampus.

An interesting outcome of our study is that the presence of FGL during MPP-LTP resulted in a heterosynaptic potentiation of the LPP. This might be interpreted as a loss of input specificity, one of the basic properties of LTP that made it originally suitable as a model for memory mechanisms, which would then imply that FGL may not engender only beneficial effects. Another possibility, more in line with the positive effects of FGL on memory (Cambon et al. 2004; Skibo et al. 2005; Secher et al. 2006, 2009; Klementiev et al. 2007), is that the apparent "heterosynaptic" LTP reflects, in fact, a facilitation of processes homosynaptic in nature, in the same way as it has been suggested for the requirement of homosynatic activity in heterosynaptic LTD (Abraham et al. 2007). Indeed, stimulation of the FGFR-1 with FGF, NCAM or L1 has been shown to induce a rise in intracellular calcium concentration $\left(\left[\mathrm{Ca}^{2+}\right] \mathrm{i}\right)$ mediated by the activation of L- and T-type voltagedependent calcium channels (VDCC) in neural as well as non-neural cell cultures (Archer et al. 1999; Rosenthal et al. 2005; Kiryushko et al. 2006). We may therefore speculate that activation by FGL of the FGFR-1 expressed on granule cells result in $\left[\mathrm{Ca}^{2+}\right] \mathrm{i}$ increase. However, as basal synaptic transmission was unchanged, we suggest that activation of the FGFR-1 may up-regulate VDCCs which can be activated by backpropagating action potentials during sustained activity (Stuart et al. 1997; Larkum et al. 1999) and are known to be closely involved in conveying dendritic calcium spikes (Larkum et al. 1999); up-regulation of VDCCs would consequently shift the modification threshold of the Bienenstock, Cooper, and Munro (BCM) curve. Such metaplasticity is a seducing alternative hypothesis to the potential loss of input specificity mentioned previously, as it would account for both the increase in homosynaptic LTP and the heterosynaptic potentiation we report herein. This hypothesis remains to be tested in vitro by producing the BCM curves with different induction protocols in the presence of FGL vs. the control peptide. Additionally, it has been shown that the NCAM-FGFR interaction activates MAPK signaling pathways via Src, which triggers gene transcription and promotes neurite outgrowth (Kiryushko et al. 2006). These events, beyond the FGL action on intracellular calcium concentration during the LTP induction phase, may also contribute to the maintenance of the enhanced late LTP we observed $24 \mathrm{~h}$ post-HFS.

Based on data showing, on one hand, that FGFR-1 is required for the generation of new neurons in the mouse hippocampus in vivo (Zhao et al. 2007) and, on the other hand, that LTP induction in the anesthetized rat increases neurogenesis in the dentate gyrus (Bruel-Jungerman et al. 2006), we sought to determine whether FGL alone or in interaction with LTP, would impact new cell proliferation in the dentate gyrus. In agreement with a previous investigation using sc injection (Aonurm-Helm et al. 2008), activation of the FGFR-1 by FGL induced no changes in cell proliferation in the dentate gyrus, suggesting that endogenous activation of FGFR-1 differs from that produced by its major ligand, FGF-2. In sharp contrast, we observed a drastic increase in the variability of the number of $\mathrm{Ki}^{+} 7^{+}$cells in the FGL group for which LTP had been induced $24 \mathrm{~h}$ earlier. This result suggests that although FGFR activation by the NCAM molecule does not directly regulate cell proliferation, it might influence the regulation that LTP exerts on neurogenesis, possibly by modifying the 
A

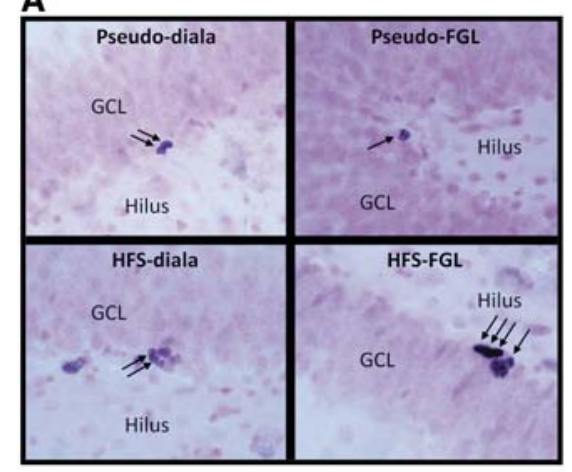

B

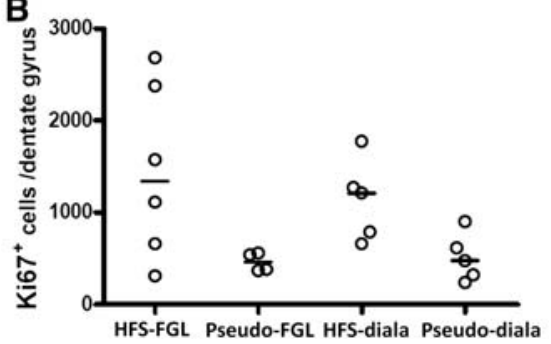

Figure 4. FGL in interaction with LTP affects adult hippocampal neurogenesis. $(A) \mathrm{Ki}^{+} 7^{+}$cells $(\uparrow)$ were primarily observed in the subgranular zone of the DG, where the hippocampal progenitor cells are located. $\mathrm{Ki} 7^{+}$cells were more abundant in the group that received HFS (GCL: granular cell layer). Scale bar $=30 \mu \mathrm{m}$. (B) FGL strikingly dysregulated new cell proliferation as shown by a significant change in variance. LTP (HFS) groups showed enhanced neurogenesis compared with pseudotetanized animals.

FGFR affinity to other ligands, such as FGF-2. The wide distribution we observed in this group may be related to the sensitivity of such regulation to the concentration of ambient FGL, which may vary between individuals notwithstanding the use of an identical protocol for each animal.

In conclusion, the current study provides the first in vivo evidence that FGL impacts functional synaptic plasticity in the hippocampus. Further, it indicates that NCAM heterophilic interactions are involved in synaptic plasticity in the adult organism. It may therefore be of particular interest to assess in future studies how NCAM interactions with other molecules (for review, Gascon et al. 2007), such as glutamate or neurotrophin receptors, might also influence synaptic efficacy.

\section{Material and Methods}

\section{FGL peptides and anti-FGL antibodies}

The FGL peptide and the control peptide (FGLdiala) were synthesized as tetrameric dendrimers composed of four monomers with the sequence EVYVVAENQQGKSKA and EVYVVAENAAGKSKA, respectively, coupled to a lysine backbone, as previously described (Kiselyov et al. 2003). The control peptide (FGL dialanine) contains a double alanine substitution in positions critical for the interaction with FGFR (Kiselyov et al. 2003). Unlike FGL, the control peptide was neither able to stimulate neurite outgrowth (Kiselyov et al. 2003; Neiiendam et al. 2004), nor to facilitate presynaptic function in vitro. Also in sharp contrast with FGL, it did not facilitate memory consolidation (Cambon et al. 2004), nor ameliorate neuropathological signs induced by $\beta$-amyloid peptide in vivo (Klementiev et al. 2007).

Rabbit polyclonal antibodies against the FGF peptide were produced as previously described (Secher et al. 2006).

\section{Experiment 1: Short-lasting plasticity}

\section{Surgery}

Twenty-six adult (300-400 g) male Sprague-Dawley rats (Charles River) were used in this experiment. All experiments in the Orsay laboratory were performed in accordance with the recommendation of the European Economic Community (EEC) (86/ $609 /$ EEC) and the French National Committee $(87 / 848)$ for care and use of laboratory animals. They were housed individually with food and water ad libitum in a temperature-controlled room and on a 12-h light/dark cycle. Animals were anesthetized with urethane (Sigma; $3.5 \mathrm{~mL} / \mathrm{kg}$ of $40 \%$ urethane in saline $0.9 \% \mathrm{NaCl}$ ) and prepared as described previously for acute recording (Doyère et al. 1997). Briefly, concentric stimulating electrodes (300 $\mu \mathrm{m}$ tip separation) were positioned in the medial (MPP) and lateral (LPP) perforant paths (MPP coordinates: $7.8 \mathrm{~mm}$ posterior and $4.2 \mathrm{~mm}$ lateral to bregma, LPP coordinates: 8.2 posterior, 5.2 lateral). Two recording electrodes, glued on a cannula for local infusion of the peptide and extending $\sim 0.5 \mathrm{~mm}$ from it, were placed in the ipsilateral dentate gyrus (DG coordinates: $4.2 \mathrm{~mm}$ posterior, $2.5 \mathrm{~mm}$ lateral to bregma). The depth of the electrodes was adjusted to maximize the slope of the positive-going field excitatory post-synaptic potential. One of the electrodes was chosen for analysis on the basis of the signal amplitude. A silver ball placed between the skull and the pial surface was used as reference and ground electrodes.

\section{Electrophysiology and experimental procedure}

Field potentials evoked by stimulation of either pathway were recorded through field effect transistors and signals were amplified, filtered (band pass $0.1 \mathrm{~Hz}$ to $3 \mathrm{kHz}$ ) and digitalized at $20 \mathrm{kHz}$ using an ITC-16 computer interface analog-digital (A/D) converter (Instrutech Corp.) coupled to a personal computer (MAC-G4, Apple Macintosh Inc.). Signals were collected using A/Dvance P3.61j software (Robert McKellar Douglas).

Standard convergence and summation tests were performed prior to the experiment in order to ensure that fibers activated by stimulation of the MPP and LPP terminated on a common set of granule cells (McNaughton and Barnes 1977; Abraham and Goddard 1983; Doyère et al. 1997). Best convergence was found when stimuli delivered to LPP preceded the MPP stimulus by 1$3 \mathrm{msec}$. In order to determine the test intensity, input/output (I/O) curves were also generated for each pathway with stimulation intensities ranging from 200 to $1000 \mu \mathrm{A}$ (duration of $120 \mu \mathrm{sec}$ ). The EPSP slope was averaged between four traces at each intensity, and the test intensity was set to elicit an EPSP slope of $50 \%$ of the maximal slope value. For baseline recordings, field potentials were evoked alternately on the two pathways at 15-sec intervals (i.e., at a frequency of $0.033 \mathrm{~Hz}$ for each pathway). In order to assess local network regulation, medial-medial (m-m) and lateral-lateral (1-1) paired-pulse tests were performed with interstimuli intervals (ISI) of 20,70 , and $500 \mathrm{msec}$. The delivery of FGL or its inactive form FGLdiala (PolyPeptide Laboratories; $1 \mathrm{mg} / \mathrm{mL}$ dissolved in saline, $0.3 \mu \mathrm{L}$ over $5 \mathrm{~min}$ ) was performed locally ( $\sim 500 \mu \mathrm{m}$ above the recording site) by means of a cannula glued to the recording electrodes and connected to a precision pump (Harvard Apparatus). The local infusion of peptides was performed after $30 \mathrm{~min}$ baseline recording. The control groups consisted in recording basal synaptic transmission for $270 \mathrm{~min}$ after peptide infusion. In the LTP group, the preparation was allowed to stabilize for $90 \mathrm{~min}$ prior to the induction of LTP and the latter was recorded for $180 \mathrm{~min}$. LTP was induced by highfrequency stimulation (HFS) trains consisting of 10 series, 1 min apart, of three trains of pulses $(400 \mathrm{~Hz}, 20 \mathrm{msec})$ at 1-sec intervals at test intensity.

\section{Experiment 2: Imaging of peptide diffusion}

We first verified that the FGL peptide rapidly reached the DG after a single icv administration by analyzing immunostaining distribution for FGL antibody at different time points after infusion. In a separate experiment performed in the laboratory in Denmark 
in accordance with European Union legislation and with a license from the Danish Animal Experiments Inspectorate, rats were perfused with saline followed by Zamboni's fixative either 10, 30,60 , or $120 \mathrm{~min}$ ( $n=4$ for each time point) following a single icv injection into the right lateral ventricle $(5 \mu \mathrm{L}$ of $2 \mathrm{mg} / \mathrm{mL}$ at $1 \mu \mathrm{L} / \mathrm{min})$. Brains were then post-fixed overnight in the same fixative and transferred to a 30\% sucrose solution in PBS for cryoprotection. Regularly spaced $30 \mu \mathrm{m}$ coronal sections were then cut and incubated with the following primary antibodies: rabbit antiFGL (1:3000, Loke Diagnostics) and mouse anti-NeuN (1:200, Chemicon, AH Diagnostics AH).

Immunoreactivity was detected using the corresponding secondary antibodies (1:200, DakoCytomation) conjugated with a fluorescent label (Alexa 488 or Alexa 546) or peroxidase (thr LSAB 2 System-HRP, DakoCytomation) for revelation with DAB (DakoCytomation). Photomicrographs were taken using the Olympus microscope based Visiopharm Integrated System (VIS 2006).

\section{Experiment 3: Long-term plasticity}

\section{Surgery}

Surgery and placements of the stimulating and recording electrode were performed as described earlier for the recording of anesthetized rats with the following exceptions: (1) animals were anesthetized with pentobarbital (Ceva; $1 \mathrm{~mL} / \mathrm{kg}$ in saline) supplemented with tolfedine (Vetoquinol; $0.01 \mathrm{~mL} / \mathrm{kg}$ in saline); (2) the cannula was placed contralaterally in the lateral ventricle (coordinates: $1.3 \mathrm{~mm}$ posterior, 1.6 lateral to bregma) for intracerebroventricular (icv) peptide delivery; (3) the recording electrodes were inserted into a stainless-steel microtube from which they extended $\sim 1.5 \mathrm{~mm}$; (4) the tube served as a reference; (5) stimulation was given only to MPP. All electrodes were then connected to multichannel miniature sockets fixed to the skull with dental acrylic (Dentalon).

\section{Electrophysiology and experimental procedure}

For data acquisition flexible recording and stimulating cables were passed through a rotating commutator at the top of the recording chamber and the field effect transistors were placed on the connecting sockets. All other parameters were identical to experiment 1.

Twenty-six rats were used in this experiment. They were allowed to recover from surgery in their home cages for 10-15 d and were then habituated to the recording chamber for $20 \mathrm{~min}$ each day for $2 \mathrm{~d}$ before starting the experiments. I/O stimulus intensities ranged between 100 and $700 \mu \mathrm{A}$ with a width of $120 \mu$ sec. The EPSP slope was averaged between four traces at each intensity and the test intensity was set to elicit an EPSP slope of $50 \%$ of the maximal slope value. Baselines were collected for three days in order to assess the stability of the responses to MPP stimulation. On the third day, the FGL or control peptide was delivered through the cannula placed contralaterally in the lateral ventricle with $5 \mu \mathrm{L}(2 \mathrm{mg} / \mathrm{mL}$, dissolved in $50 \%$ distilled water $/ 50 \%$ saline), over $5 \mathrm{~min}$, a dose that had been proved to be efficient in promoting memory in behavioral experiments (Cambon et al. 2004). Immediately after the infusion, rats were placed in the recording chamber, and a $30 \mathrm{~min}$ baseline was recorded. Then, HFS or a pseudo-tetanus (Pseudo) was applied to the MPP, and followed by a further $20 \mathrm{~min}$ of recording. HFS protocol consisted in six series, 2 min apart, of six trains of pulses $(400 \mathrm{~Hz}, 20 \mathrm{msec})$ at 10 -sec intervals and the pseudotetanus consisted in six series, $2 \mathrm{~min}$ apart, of six pulses at 10 -sec intervals at test intensity. Finally, baselines were also collected for $20 \mathrm{~min}$ on the fourth day, $24 \mathrm{~h}$ following the delivery of HFS or Pseudo.

\section{Analysis of hippocampal progenitor cell proliferation}

Neurogenic activity in the adult hippocampus was evaluated in a subgroup of rats perfused with $4 \%$ paraformaldehyde, $24 \mathrm{~h}$ after LTP induction. Immunohistochemistry against Ki67 protein, a marker of cell proliferation, was used to determine the number of proliferating cells in the DG. Brain coronal sections were treated for endogeneous peroxidases inactivation with $3 \% \mathrm{H}_{2} \mathrm{O}_{2}$ in $10 \%$ methanol/PBS before being blocked with normal goat serum/bovine serum albumin/Tween-20 in PBS-Triton X-100. Incubation with rabbit anti-Ki67 antibody (Neomarkers) diluted 1: 2000 in blocking buffer followed for $72 \mathrm{~h}$ at $4^{\circ} \mathrm{C}$. After incubation with the secondary antibody (goat anti-rabbit IgG-biotin, diluted 1:400 in PBS-T) and avidin-biotin-peroxidase complex (Vector Laboratories Elite Kit) diluted 1:500 in PBST, the peroxidase immunolabeling was visualized with diaminobenzidine containing nickel. Sections were mounted onto subbed slides, counterstained with Nuclear Fast Red (Vector Laboratories), dehydrated and coverslipped.

\section{Quantification of immunostaining}

Labeling and cell-counting procedures were conducted by an experimenter blind to the experimental conditions. Ki67 immunopositive $\left(\mathrm{Ki}_{67} 7^{+}\right)$cells were counted for each animal, on sections spanning the dorsal dentate gyrus ipsilateral to the stimulation (HFS or Pseudo) and spaced $240 \mu \mathrm{m}$ (series of one-in-six sections; $40 \mu \mathrm{m}$ thick), as previously described (Trouche et al. 2009). Briefly, the area comprising the granular and subgranular cell layers of the dentate gyrus was measured in square millimeters on each section with Mercator software (Explora Nova). The sum of all surfaces sampled for each mouse was multiplied with the sections thickness to calculate the sectional volume. It was multiplied with the spacing of the sections to calculate the reference volume. To obtain the total number of Ki67 immunolabeled cells per dentate gyrus, the ratio of counted immunopositive cells per sectional volume was multiplied by the reference volume.

\section{Statistical analyses}

Data for each condition were pooled irrespective of experimental outcome and are expressed as mean \pm SEM. Statistical analyses was performed by ANOVA using Statview 5.0 (SAS Institute Inc.) unless stated otherwise. LTP values were calculated as the change in mean fEPSP slope between the baseline and 20 min of recording either 3 or $24 \mathrm{~h}$ after HFS. PTP values were calculated by averaging over a period of 2 min following HFS (starting $15 \mathrm{sec}$ after the last stimulation train), and values were then expressed as the percent of baseline change in mean fEPSP slope. Paired-pulse ratios were calculated using the following formula: $(\mathrm{S} 2 / \mathrm{S} 1 \times 100)-100$, where $\mathrm{S} 1$ and S2 are the amplitude of the first and second population spike, respectively.

\section{Acknowledgments}

We thank Gérard Dutrieux, Paulette Richer, Nathalie Samson, and Valérie Marsaux-Halin at the CNPS (former NAMC) for their excellent technical assistance. We are also grateful to Dr. Austen Milnerwood for comments on the manuscript. This work was supported by the EU FP6 Promemoria program (Contract No. 512012).

\section{References}

Abraham WC, Goddard GV. 1983. Asymmetric relationships between homosynaptic long-term potentiation and heterosynaptic long-term depression. Nature 305: 717-719.

Abraham WC, McNaughton N. 1984. Differences in synaptic transmission between medial and lateral components of the perforant path. Brain Res 303: $251-260$.

Abraham WC, Logan B, Wolff A, Benuskova L. 2007. Heterosynaptic LTD in the dentate gyrus of anesthetized rat requires homosynaptic activity. J Neurophysiol 98: 1048-1051.

Alger BE, Nicoll RA. 1980. Spontaneous inhibitory post-synaptic potentials in hippocampus: Mechanism for tonic inhibition. Brain Res 200: 195-200.

Andersen P, Eccles JC, Loyning Y. 1964. Pathway of postsynaptic inhibition in the hippocampus. J Neurophysiol 27: 608-619.

Aonurm-Helm A, Jurgenson M, Zharkovsky T, Sonn K, Berezin V, Bock E, Zharkovsky A. 2008. Depression-like behaviour in neural cell adhesion 
molecule (NCAM)-deficient mice and its reversal by an NCAM-derived peptide. FGL 28: $1618-1628$.

Archer FR, Doherty P, Collins D, Bolsover SR. 1999. CAMs and FGF cause a local submembrane calcium signal promoting axon outgrowth without a rise in bulk calcium concentration. Eur J Neurosci 11: $3565-3573$.

Becker CG, Artola A, Gerardy-Schahn R, Becker T, Welzl H, Schachner M. 1996. The polysialic acid modification of the neural cell adhesion molecule is involved in spatial learning and hippocampal long-term potentiation. J Neurosci Res 45: 143-152.

Bliss TV, Collingridge GL. 1993. A synaptic model of memory: Long-term potentiation in the hippocampus. Nature 361: 31-39.

Bordi F, Reggiani A, Conquet F. 1997. Regulation of synaptic plasticity by mGluR1 studied in vivo in mGluR1 mutant mice. Brain Res 761: 121-126.

Bozon B, Kelly A, Josselyn SA, Silva AJ, Davis S, Laroche S. 2003. MAPK, CREB and zif268 are all required for the consolidation of recognition memory. Philos Trans R Soc Lond B Biol Sci 358: 805-814.

Bruel-Jungerman E, Davis S, Rampon C, Laroche S. 2006. Long-term potentiation enhances neurogenesis in the adult dentate gyrus. J Neurosci 26: 5888-5893.

Cambon K, Hansen SM, Venero C, Herrero AI, Skibo G, Berezin V, Bock E, Sandi C. 2004. A synthetic neural cell adhesion molecule mimetic peptide promotes synaptogenesis, enhances presynaptic function, and facilitates memory consolidation. J Neurosci 24: 4197-4204.

Ditlevsen DK, Povlsen GK, Berezin V, Bock E. 2008. NCAM-induced intracellular signaling revisited. J Neurosci Res 86: 727-743.

Downer EJ, Cowley TR, Lyons A, Mills KH, Berezin V, Bock E, Lynch MA. 2010. A novel anti-inflammatory role of NCAM-derived mimetic peptide, FGL. Neurobiol Aging 31: 118-128.

Doyère V, Srebro B, Laroche S. 1997. Heterosynaptic LTD and depotentiation in the medial perforant path of the dentate gyrus in the freely moving rat. J Neurophysiol 77: 571-578.

Eckhardt M, Bukalo O, Chazal G, Wang L, Goridis C, Schachner M, Gerardy-Schahn R, Cremer H, Dityatev A. 2000. Mice deficient in the polysialyltransferase ST8SiaIV/PST-1 allow discrimination of the roles of neural cell adhesion molecule protein and polysialic acid in neural development and synaptic plasticity. J Neurosci 20: $5234-5244$.

Fricke RA, Prince DA. 1984. Electrophysiology of dentate gyrus granule cells. J Neurophysiol 51: 195-209.

Fueta Y, Schwarz W, Ohno K, Endo Y, Mita T. 2002. Selective suppression of hippocampal region hyperexcitability related to seizure susceptibility in epileptic El mice by the GABA-transporter inhibitor tiagabine. Brain Res 947: 212-217.

Gascon E, Vutskits L, Kiss JZ. 2007. Polysialic acid-neural cell adhesion molecule in brain plasticity: From synapses to integration of new neurons. Brain Res Rev 56: 101-118.

Hinsby AM, Berezin V, Bock E. 2004a. Molecular mechanisms of NCAM function. Front Biosci 9: 2227-2244.

Hinsby AM, Lundfald L, Ditlevsen DK, Korshunova I, Juhl L, Meakin SO, Berezin V, Bock E. 2004b. ShcA regulates neurite outgrowth stimulated by neural cell adhesion molecule but not by fibroblast growth factor 2: Evidence for a distinct fibroblast growth factor receptor response to neural cell adhesion molecule activation. J Neurochem 91: 694-703.

Hisajima H, Saito H, Abe K, Nishiyama N. 1992. Effects of acidic fibroblast growth factor on hippocampal long-term potentiation in fasted rats. I Neurosci Res 31: 549-553.

Kee N, Sivalingam S, Boonstra R, Wojtowicz JM. 2002. The utility of Ki-67 and BrdU as proliferative markers of adult neurogenesis. J Neurosci Methods 115: 97-105.

Kiryushko D, Korshunova I, Berezin V, Bock E. 2006. Neural cell adhesion molecule induces intracellular signaling via multiple mechanisms of $\mathrm{Ca}^{2+}$ homeostasis. Mol Biol Cell 17: 2278-2286.

Kiselyov VV, Skladchikova G, Hinsby AM, Jensen PH, Kulahin N, Soroka V, Pedersen N, Tsetlin V, Poulsen FM, Berezin V, et al. 2003. Structural basis for a direct interaction between FGFR1 and NCAM and evidence for a regulatory role of ATP. Structure 11: 691-701.

Kiselyov VV, Soroka V, Berezin V, Bock E. 2005. Structural biology of NCAM homophilic binding and activation of FGFR. J Neurochem 94: $1169-1179$

Klementiev B, Novikova T, Novitskaya V, Walmod PS, Dmytriyeva O, Pakkenberg B, Berezin V, Bock E. 2007. A neural cell adhesion molecule-derived peptide reduces neuropathological signs and cognitive impairment induced by $\mathrm{A}_{25-35}$. Neuroscience 145: 209-224.

Larkum ME, Kaiser KM, Sakmann B. 1999. Calcium electrogenesis in distal apical dendrites of layer 5 pyramidal cells at a critical frequency of backpropagating action potentials. Proc Natl Acad Sci 96: 14600-14604.

Luthi A, Laurent JP, Figurov A, Muller D, Schachner M. 1994. Hippocampal long-term potentiation and neural cell adhesion molecules L1 and NCAM. Nature 372: 777-779.

Luthi A, Mohajeri H, Schachner M, Laurent JP. 1996. Reduction of hippocampal long-term potentiation in transgenic mice ectopically expressing the neural cell adhesion molecule L1 in astrocytes. J Neurosci Res 46: $1-6$.

Maness PF, Schachner M. 2007. Neural recognition molecules of the immunoglobulin superfamily: Signaling transducers of axon guidance and neuronal migration. Nat Neurosci 10: 19-26.

McNaughton BL. 1980. Evidence for two physiologically distinct perforant pathways to the fascia dentata. Brain Res 199: 1-19.

McNaughton BL, Barnes CA. 1977. Physiological identification and analysis of dentate granule cell responses to stimulation of the medial and lateral perforant pathways in the rat. J Comp Neurol 175: 439-454.

Neiiendam JL, Køhler LB, Christensen C, Li S, Pedersen MV, Ditlevsen DK, Kornum MK, Kiselyov VV, Berezin V, Bock E. 2004. An NCAMderived FGF-receptor agonist, the FGL-peptide, induces neurite outgrowth and neuronal survival in primary rat neurons. J Neurochem 91: $920-935$

Popov VI, Medvedev NI, Kraev IV, Gabbott PL, Davies HA, Lynch M, Cowley TR, Berezin V, Bock E, Stewart MG. 2008. A cell adhesion molecule mimetic, FGL peptide, induces alterations in synapse and dendritic spine structure in the dentate gyrus of aged rats: A three-dimensional ultrastructural study. Eur J Neurosci 27: 301-314.

Racine RJ, Milgram NW. 1983. Short-term potentiation phenomena in the rat limbic forebrain. Brain Res 260: 201-216.

Ronn LC, Bock E, Linnemann D, Jahnsen H. 1995. NCAM-antibodies modulate induction of long-term potentiation in rat hippocampal CA1. Brain Res 677: 145-151.

Rosenthal R, Malek G, Salomon N, Peill-Meininghaus M, Coeppicus L, Wohlleben H, Wimmers S, Bowes Rickman C, Strauss O. 2005. The fibroblast growth factor receptors, FGFR-1 and FGFR-2, mediate two independent signalling pathways in human retinal pigment epithelial cells. Biochem Biophys Res Commun 337: 241-247.

Ruan DY, Chen JT, Zhao C, Xu YZ, Wang M, Zhao WF. 1998. Impairment of long-term potentiation and paired-pulse facilitation in rat hippocampal dentate gyrus following developmental lead exposure in vivo. Brain Res 806: 196-201.

Secher T, Novitskaia V, Berezin V, Bock E, Glenthoj B, Klementiev B. 2006. A neural cell adhesion molecule-derived fibroblast growth factor receptor agonist, the FGL-peptide, promotes early postnatal sensorimotor development and enhances social memory retention. Neuroscience 141: $1289-1299$.

Secher T, Berezin V, Bock E, Glenthoj B. 2009. Effect of an NCAM mimetic peptide FGL on impairment in spatial learning and memory after neonatal phencyclidine treatment in rats. Behav Brain Res 199: $288-297$.

Skibo GG, Lushnikova IV, Voronin KY, Dmitrieva O, Novikova T, Klementiev B, Vaudano E, Berezin VA, Bock E. 2005. A synthetic NCAM-derived peptide, FGL, protects hippocampal neurons from ischemic insult both in vitro and in vivo. Eur J Neurosci 22: 1589-1596.

Steffensen SC, Henriksen SJ. 1991. Effects of baclofen and bicuculline on inhibition in the fascia dentata and hippocampus regio superior. Brain Res 538: 46-53.

Stewart M, Popov V, Medvedev N, Gabbott P, Corbett N, Kraev I, Davies H. 2010. Dendritic spine and synapse morphological alterations induced by a neural cell adhesion molecule mimetic. In Advances in Experimental Medicine and Biology: Structure and Function of the Neural Cell adhesion Molecule NCAM (ed. V Berezin), Vol. 663: 373-383. Springer, New York.

Stoenica L, Senkov O, Gerardy-Schahn R, Weinhold B, Schachner M, Dityatev A. 2006. In vivo synaptic plasticity in the dentate gyrus of mice deficient in the neural cell adhesion molecule NCAM or its polysialic acid. Eur J Neurosci 23: 2255-2264.

Stuart G, Schiller J, Sakmann B. 1997. Action potential initiation and propagation in rat neocortical pyramidal neurons. J Physiol 505: 617-632.

Trouche S, Bontempi B, Roullet P, Rampon C. 2009. Recruitment of adult-generated neurons into functional hippocampal networks contributes to updating and strengthening of spatial memory. Proc Natl Acad Sci 106: 5919-5924.

Walmod PS, Kolkova K, Berezin V, Bock E. 2004. Zippers make signals: NCAM-mediated molecular interactions and signal transduction. Neurochem Res 29: 2015-2035.

Wang M, Chen JT, Ruan DY, Xu YZ. 2001. Vasopressin reverses aluminum-induced impairment of synaptic plasticity in the rat dentate gyrus in vivo. Brain Res 899: 193-200.

Yuste R, Bonhoeffer T. 2001. Morphological changes in dendritic spines associated with long-term synaptic plasticity. Annu Rev Neurosci 24: 1071-1089.

Zhao M, Li D, Shimazu K, Zhou YX, Lu B, Deng CX. 2007. Fibroblast growth factor receptor-1 is required for long-term potentiation, memory consolidation, and neurogenesis. Biol Psychiatry 62: 381-390.

Received January 28, 2011; accepted in revised form February 23, 2011. 


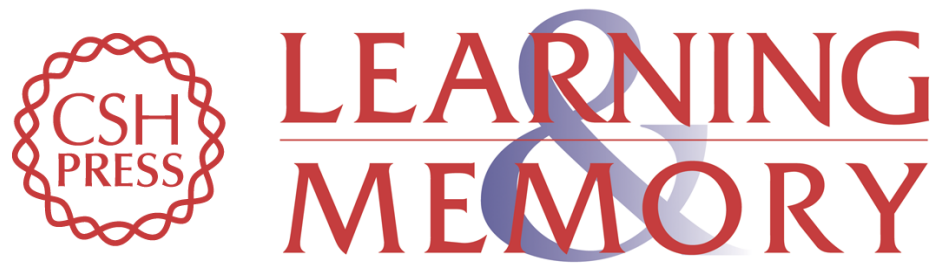

\section{The neural cell adhesion molecule-derived peptide FGL facilitates long-term plasticity in the dentate gyrus in vivo}

Glenn Dallérac, Meike Zerwas, Tatiana Novikova, et al.

Learn. Mem. 2011, 18:

Access the most recent version at doi:10.1101//m.2154311

Supplemental
Material http://learnmem.cshlp.org/content/suppl/2011/04/20/18.5.306.DC1

References This article cites 52 articles, 6 of which can be accessed free at:

http://learnmem.cshlp.org/content/18/5/306.full.html\#ref-list-1

License

Email Alerting Receive free email alerts when new articles cite this article - sign up in the box at the Service top right corner of the article or click here. 